\title{
Clinical findings in 32 patients with 22q11.2 microdeletion attended in the city of Córdoba, Argentina
}

\author{
Cecilia del Carmen Montes, M.D. ${ }^{a, b}$, Alicia Sturich, Biologista, ${ }^{n,}$,Alejandra Chaves, B.S. ${ }^{a}$, Ernesto Juaneda, M.D. ${ }^{c}$, \\ Julio Orellana, M.D. ${ }^{d}$, Roberto De Rossi, M.D. ${ }^{e}$, Blanca Pereyra, B.S. ${ }^{a}$, Luis Alday, M.D. ${ }^{c}$, and \\ Norma Teresa Rossi, M.D., ${ }^{a, b}$
}

\begin{abstract}
The 22q11.2 microdeletion is the most common deletion syndrome, with a prevalence of $1 / 4000-1 / 6000$ among newborn infants and a wide phenotypic variability. The diagnosis of the 22q11.2 microdeletion is made through cytogenetics or fluorescence in situ hybridization (FISH). The objectives of this article were to describe the clinical features of 32 patients with 22q11.2 microdeletion and the findings of other chromosomal abnormalities and genetic syndromes in phenotypically similar patients. This series was made up of 268 patients with clinical criteria supporting the diagnostic suspicion attended at the Hospital de Niños and Hospital Privado, of Córdoba, between March $1^{\text {st }}, 2004$ and August $31^{\text {st }}, 2011$. The following parameters were analyzed: age at the time of the diagnosis, sex, clinical manifestations, and mortality. Thirty-two patients (19 males and 13 females) had a positive result for this deletion. The diagnosis was made mostly in their first months and years of life (age range: 7 days old-31 years old). The clinical manifestations were: congenital heart diseases (22/32), thymic hypoplasia-agenesis / recurrentinfections (10/32), velopalatal insufficiency $(8 / 32)$. Five patients died; four due to a complication associated with their cardiovascular disease and one due to multiple organ failure. The clinical manifestations of the syndrome were varied. Key words: 22qll.2 microdeletion, FISH 22qll.2, DiGeorge/velocardio-facial syndrome, congenital heart disease.
\end{abstract}

http:/ /dx.doi.org/10.5546/aap.2013.423

a. Genetic Medicine Department, Hospital de Niños de la Santísima Trinidad, Córdoba.

b. Genetic Medicine Division, Hospital Privado, Centro Médico Córdoba.

c. Cardiology Service.

d. Allergy and Immunology Department.

e. Cardiovascular Surgery Service.

Hospital de Niños de la Santísima Trinidad, Córdoba.

E-mail Address:

Cecilia del Carmen Montes, M.D.: ceciliamontes69@hotmail. com

Funding: Grant provided for Recently Formed Groups by the Ministry of Science and Technology of Córdoba and the School of Medicine of Universidad Católica de Córdoba.

\section{Conflict of interest:}

None.

Received: 01-27-2013

Accepted: 07-10-2013

\section{INTRODUCTION}

The 22q11.2 microdeletion is the most common cause of microdeletion in human beings and has a prevalence of 1/4000-1/6000 among live newborn infants. Approximately $95 \%$ of the cases are diagnosed when a loss of genetic material is observed through the fluorescence in situ hybridization (FISH) technique. Tobías, et al. recommend the use of the FISH technique for the 22q11.2 microdeletion in patients with conotruncal heart defects, or in the parents of patients with 22q11.2 microdeletion, or when a patient has two or more of the following clinical findings: facial dysmorphism (short and downslanting palpebral fissure, small ears, a long nose with a bulbous tip, a small mouth, micrognathia), non-conotruncal heart defects, cleft palate, velopharyngeal insufficiency, developmental delay/learning disability, immune system abnormalities/thymic hypoplasia. ${ }^{1}$

Other clinical characteristics include attention deficit disorder and psychiatric disorders. ${ }^{2}$ Heart diseases vary, but conotruncal heart defects are the most frequent. ${ }^{3}$

Inherited defects account for $5-10 \%$ of all cases; and for their diagnosis, it is necessary to study patients' parents. ${ }^{4}$

The objectives of this article were to describe the clinical features of 32 patients with 22q11.2 microdeletion and the findings of other chromosomal abnormalities and genetic syndromes in phenotypically similar patients.

\section{DESCRIPTION}

A retrospective, observational study was conducted with 268 patients with suspected $22 \mathrm{q} 11.2$ microdeletion syndrome as per the criteria listed by Tobías, et al. ${ }^{1}$ attended at the Genetic Medicine Departments of the Hospital de Niños and Hospital Privado, of Córdoba, between March 1 1', 2004 and August 31 $1^{\text {st }}, 2011$. All patients, and the parents of those with positive results, were assessed by a geneticist and referred to the corresponding specialist consultation. The lab diagnosis was performed with CTC banding cytogenetics and FISH. For the FISH technique, an LSI Di Ceorge/VCFS locus-specific 
probe, dual color, with 22q11.2 critical region and orange spectrum from Vysis Laboratories (Abbott Molecular Inc.) was used, with a control probe for 22q13.3 region with a green spectrum.

The presence of two orange signals and two green signals per cell in $100 \%$ of metaphases and in $90 \%$ of interphase nuclei was considered normal; the presence of an orange signal and two green signals per cell was considered positive for microdeletion; the presence of normal cells and deleted cells in $10 \%$ of metaphase cells and in $15 \%$ of interphase cells was considered a mosaic microdeletion, ${ }^{5}$ and the presence of three orange signals and two green signals or two orange signals, with one of these having an intensity that doubled the normal signal and two green signals was considered a microduplication (Figure l). ${ }^{6}$

The analyzed outcome variables were as follows: age at the time of the diagnosis, sex, clinical manifestations, and mortality.

Out of the 268 patients who met the clinical criteria for FISH, 32 were diagnosed with a 22q11.2 microdeletion (11.94\%).

Out of the positive patients, 19 were males. Age ranged from 7 days old to 31 years old.

Most patients were diagnosed in their first months of life or during childhood, with isolated cases found during adolescence and adulthood.

No patients had a diagnosis of a mosaic microdeletion or a microduplication of the

FIgURe 1. A. Negative FISH, two orange regions and two green regions. B. Positive FISH, an orange region and two green regions. $C$ and D. Evolutionary phenotype of two patients with 22qll.2 microdeletion (5 and 9 years old)

A

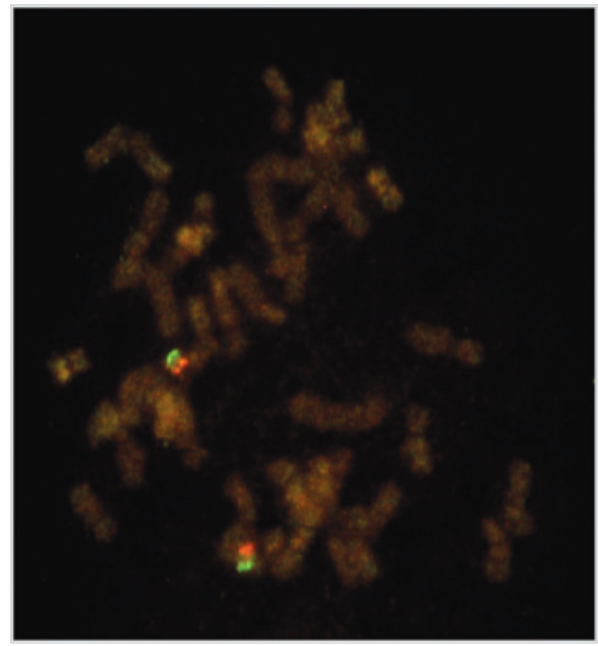

C

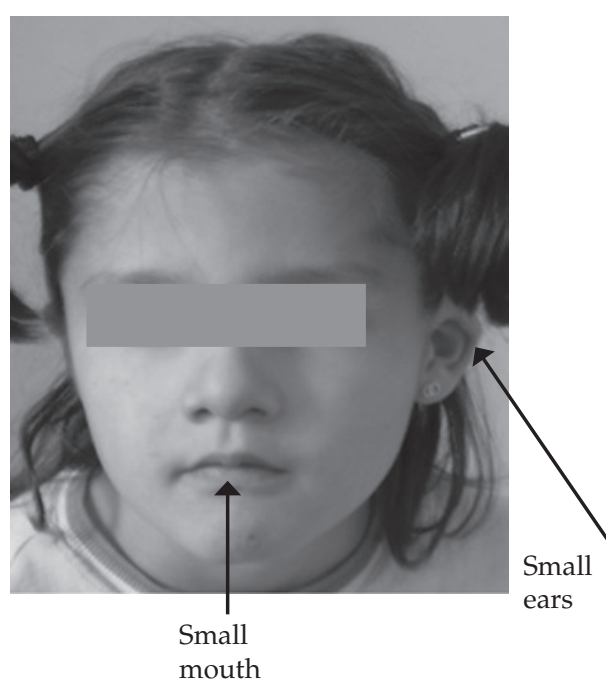

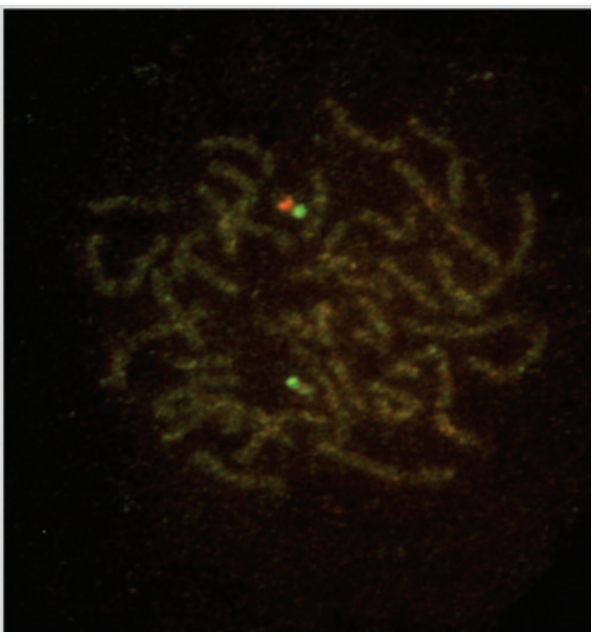

$\mathrm{D}$

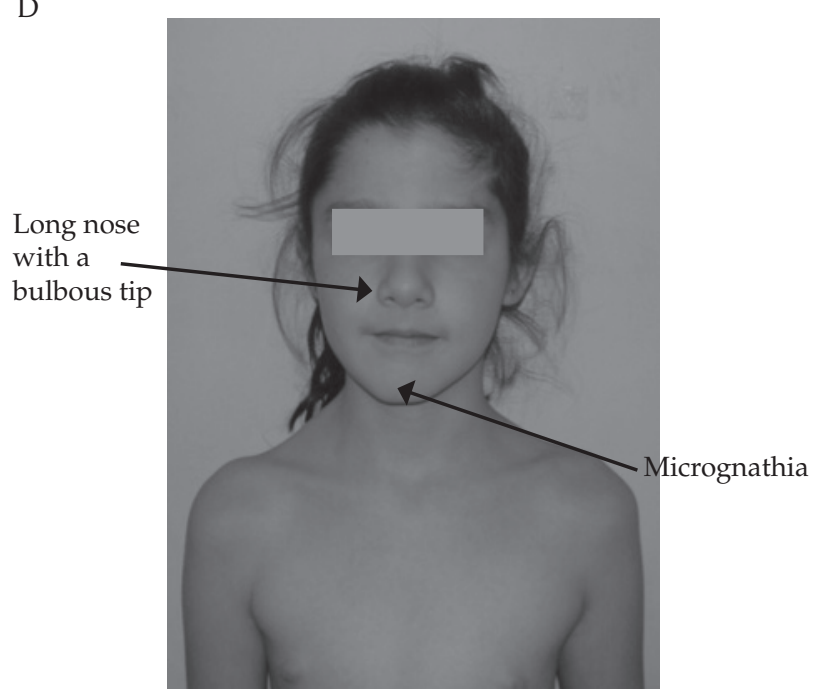


22q11.2 critical region. In two patients the deletion was detected by cytogenetic techniques.

Tests were performed on both parents in 8 cases, and on the mother only in 1 case; a microdeletion was found in only one of them. No data are available for the other 24 parents. Congenital heart diseases were found in 22 patients, with a predominance of conotruncal heart defects; all of them also had other associated phenotypic features (Table 1).

In addition, thymic hypoplasia-agenesis or recurrent infections were observed in 10 patients; a cleft palate was observed in 5, three of them were cases of submucous cleft palate; velopalatal insufficiency was found in 8; scoliosis in 4; craniosynostosis in 2; and systemic rheumathoid arthritis in 2. Other symptoms, such as asymmetric crying facies, hypoparathyroidism with seizures due to hypocalcaemia, microcornea and opaque cornea, anterior displacement of the anus, and chronic idiopathic thrombocytopenic purpura, were observed in one patient.

Five children died in their first year of life; 4 due to a heart disease related complication and 1 due to multiple organ failure.

A differential diagnosis was made in 16 of the patients who were negative for the 22q11.2 microdeletion. Other chromosomal abnormalities were found in 7: a) paracentric inversion of the chromosome $2 ; b$ ) mosaic ring chromosome $13 ;$ c) translocation $(10 q ; 8 q) ; d)$ 4 p16 microdeletion; e) mosaic duplication (15)

TABLE 1. Sex, age at the time of diagnosis and type of congenital heart disease in patients with 22qll.2 microdeletion

\begin{tabular}{|c|c|c|c|}
\hline Patient & Sex & Age at the time of diagnosis & Congenital heart disease \\
\hline 1 & Female & 7 days old & Aorta intraventricular coarctation and patent ductus arteriosus* \\
\hline 2 & Male & 7 years old & Pulmonary stenosis, ventricular septal defect* \\
\hline 3 & Male & 21 days old & Atrial septal defect, patent ductus arteriosus \\
\hline 4 & Male & 1 month old & Tetralogy of Fallot* \\
\hline 5 & Male & 3 months old & Tetralogy of Fallot with pulmonary atresia* \\
\hline 6 & Male & 19 years old & Ventricular septal defect \\
\hline 7 & Female & 30 years old & Pulmonary stenosis, ventricular septal defect* \\
\hline 8 & Female & 5 years old & Truncus arteriosus type $\mathrm{II}^{*}$ \\
\hline 9 & Male & 6 years old & Patent ductus arteriosus \\
\hline 10 & Male & 9 years old & Tetralogy of Fallot* \\
\hline 11 & Female & 31 years old & Atrial septal defect, pericardial agenesis \\
\hline 12 & Male & 5 months old & Tetralogy of Fallot with pulmonary agenesis* \\
\hline 13 & Female & 6 years old & Bicuspid aortic valve, mild aortic insufficiency \\
\hline 14 & Female & 3 years old & Interruption of the aortic arch, ventricular septal defect* \\
\hline 15 & Female & 2 months old & $\begin{array}{l}\text { Pulmonary atresia, ventricular septal defect, patent ductus arteriosus, } \\
\text { major aortopulmonary collateral arteries, } \\
\text { aberrant right subclavian artery* }\end{array}$ \\
\hline 16 & Male & 3 years old & Tetralogy of Fallot with absence of supraventricular crest* \\
\hline 17 & Male & 1 month old & Pulmonary atresia with major aortopulmonary collateral arteries* \\
\hline 18 & Female & 12 years old & Tetralogy of Fallot* \\
\hline 19 & Female & 11 years old & Atrial septal defect, right aortic arch* \\
\hline 20 & Male & 3 years old & Supracristal ventricular septal defect* \\
\hline 21 & Male & 3 years old & Tetralogy of Fallot* \\
\hline 22 & Male & 16 days old & Truncus arteriosus type $\mathrm{I}^{*}$ \\
\hline
\end{tabular}

* Conotruncal defect. 
(q13q24); f) robertsonian translocation (15;22); and g) translocation $(9 q ; 22 q)$ (see phenotypes in Table 2). The remaining 9 patients were diagnosed with other genetic syndromes: Cayler syndrome, otopalatodigital syndrome, Charge syndrome, Opitz G/BBB syndrome, Stickler syndrome, Rubinstein-Taybi syndrome, frontonasal dysplasia with acromelic involvement, Noonan syndrome, and Alagille syndrome.

\section{DISCUSSION}

The 22q11.2 microdeletion was detected in $11.94 \%$ of patients with clinical suspicion.

Such prevalence is similar to that obtained by Kitsiou-tzeli, et al., ${ }^{7}$ who reported a $12.2 \%$ rate, in addition to other chromosomal abnormalities in 2 patients (1.4\%). Brunet, et al. studied 295 patients referred to the detection of the 22q11.2 deletion by FISH and cytogenetic techniques; the diagnosis was confirmed in 12 patients ( $4 \%$ ) and other chromosomal rearrangements in 5; no microduplication was observed. ${ }^{6}$ Our higher rate, compared to that of Brunet, may be explained by the fact that patients included in our series were clinically evaluated by geneticists. Halder, et al. published a study with a prevalence of $6.16 \%$ in patients with congenital heart diseases from a site in India. In that series, as in our study, all diagnosed patients had extracardiac manifestations. ${ }^{8}$
In our sample, 7 patients were diagnosed with chromosomal abnormalities and negative microdeletion. Brunet ${ }_{6}$ and Kitsiou-tzeli ${ }^{7}$ also referred abnormalities in the 2, 10 and 13 chromosome pairs, although the chromosome regions involved varied from those of our patients. Chromosomal abnormalities diagnosed in those patients with no 22q11.2 microdeletion in our series, similarly to what has been described by other authors, ${ }^{6,7}$ may suggest the presence of other genetic loci or epigenetic factors which may also be related to the clinical phenotype of the 22q11.2 microdeletion (Table 2).

Clinically diagnosed genetic syndromes in our sample were similar to those reported by Kitsioutzeli. $^{7}$

In terms of age at the time of diagnosis, the diagnosis was made early (during the first months of life and childhood) in patients referred by doctors capable of recognizing the inducer phenotype and who work together with a geneticist. As reported by Ballesta Martínez, et al., a late diagnosis may be related to being unaware of the phenotypic variability and the unavailability of diagnostic techniques. ${ }^{9}$

In our patients, the frequency and type of heart diseases related to the $22 \mathrm{q} 11.2$ microdeletion were consistent with those described in the literature, with a higher incidence of tetralogy of Fallot,

TABLE 2. Chromosomal abnormalities and clinical manifestations in patients negative for the 22qll.2 microdeletion

\begin{tabular}{|c|c|c|}
\hline Chromosomal abnormality & Formula & Clinical manifestation \\
\hline 4 p16 microdeletion & ish del(4)(p16.2p16.2)(WHS-) & $\begin{array}{l}\text { Cleft lip and palate, conotruncal heart defect, } \\
\text { hypogonadism, lipocele }\end{array}$ \\
\hline Paracentric inversion of chromosome 2 & $46, X X, \operatorname{inv}(2)(p 11 q 33)$ & $\begin{array}{l}\text { Long face, nose with a bulbous tip, hearing } \\
\text { loss, mental retardation }\end{array}$ \\
\hline Mosaic duplication of chromoción 15 & $46, X X, \operatorname{dup}(15)(q 13 q 24) / 46, X X$ & $\begin{array}{l}\text { Long face, nasal reflux, patent ductus } \\
\text { arteriosus, limited speech, mental retardation }\end{array}$ \\
\hline Robertsonian translocation $(15 ; 22)$ & $45, X Y$, rob $(15 ; 22)(q 10 ; q 10)$ pat & $\begin{array}{l}\text { Hipotonicity, nasal reflux, bulbous nose, } \\
\text { speech retardation }\end{array}$ \\
\hline Partial monosomy $9 q$ and partial trisomy $22 q$ & $\begin{array}{l}\text { 46,XY,der(9)t(9;22) } \\
\text { (q34;q13.1) mat }\end{array}$ & $\begin{array}{l}\text { Developmental failure, limb abnormalities. } \\
\text { Tetralogy of Fallot }\end{array}$ \\
\hline Partial trisomy $8 \mathrm{q}$ and partial monosomy $10 \mathrm{q}$ & $\begin{array}{l}46, X X, \operatorname{der}(10) \mathrm{t}(8 ; 10) \\
\text { (q24.1q26) pat }\end{array}$ & $\begin{array}{l}\text { Facial dysmorphism, developmental delay, } \\
\text { no speech }\end{array}$ \\
\hline $\begin{array}{l}\text { Ring chromosome and mosaic complete } \\
\text { monosomy of chromosome } 13\end{array}$ & $46, X Y, r(13) / 45, X Y-13$ & $\begin{array}{l}\text { Delayed growth, long face, long and thin } \\
\text { fingers, small ears, scoliosis }\end{array}$ \\
\hline
\end{tabular}


followed by septal defects and pulmonary valve abnormalities. $^{3}$

An atrial septal defect with complete agenesis of the pericardium, observed in one of our patients and which was considered relevant for publication, ${ }^{10}$ has not been described by other authors in relation to this syndrome.

In our series, the frequency and type of cleft palate and velopalatal insufficiency are comparable to those reported by Shprintzen. ${ }^{11}$

In agreement with the bibliography, an intrafamily variability between the patient with a maternally-inherited 22q11.2 microdeletion and her mother was observed.

The daughter had a severe phenotype and died in the neonatal period while her mother had a milder phenotype and recurrent miscarriages; to date, such association has not been reported by other publications. The maternal origin was the only inherited presentation diagnosed in our series and this is consistent with other authors' reports indicating that inheritable microdeletions are more frequently transmitted by the mother. ${ }^{12}$

Anorectal abnormalities, scoliosis, sclerocornea and microcornea have also been described by other authors. ${ }^{13,15}$

\section{CONCLUSIONS}

The 22q11.2 microdeletion syndrome has a wide phenotypic variability. Health team members should be watchful and aware of the clinical variability of this syndrome and work with a team approach to make an early diagnosis of these patients.

\section{Acknowledgments}

To all the patients and their family members, for consenting to the publication of these data, and to the specialists, for referring their patients and following on their course.

\section{REFERENCES}

1. Tobías ES, Morrison N, Whiteford ML, Tolmie Jl. Towars earlier diagnosis of 22q11 deletions. Arc Dis Child 1999;81(6):513-4.

2. Botto LD, May K, Fernhoff PM, Correa A, et al. A populationbased study of the 22q11.2deletion: phenotype, incidence, and contribution to major birth defects in the population. Pediatrics 2003;112(1 Pt 1):101-7.

3. Momma K. Cardiovascular Anomalies Associated with Chromosome 22q11.2 Deletion Syndrome. Am J Cardiol 2010;105:1617-24.

4. Ryan AK, Goodship JA, Wilson DI, Philip N, et al. Spectrum of clinical features associated with interstitial chromosome 22q11 deletions: a European collaborative study. J Med Genet 1997;3(10)4:789-804.

5. Halder A, Jaim M, Kabra M, Grupta N. Mosaic 22q11.2 microdeletion syndrome: diagnosis and clinical manifestations of two cases. Mol Cytogenet 2008;1:18.

6. Brunet A, Gabau E, Perich RM, Valdesoiro L, et al. Microdeletión and microduplication 22q11.2 screening in 295 patients with clinical features of DiGeorgeIVelocardiofacial Syndrome. Am J Med Genet A 2006;140(22):2426-32.

7. Kitsiou-tzeli S, Kolialexl A, Fryssira H, Galla-Voumvouraki A, et al. Detection of 22q11.2 deletion among 139 patients with Di GeorgeIvelocardiofacial syndrome features. In Vivo 2004;18(5):603-8.

8. Halder A, Jain M, Chaudhary I, Kabra M. Prevalence of 22q11.2 microdeletion in 146 patients with cardiac malformation in a referral hospital of North India. BMC Med Genet 2010;11:101.

9. Ballesta Martínez MJ, Guillén Navarro E, López Expósito I, Bafalliu Vidal JA, et al. Revisión de 22 casos de deleción 22q11.2: espectro fenotípico. An Pediatri (Barc) 2008;69(4):304-10.

10. Juaneda E, Alday LE, Moreyra E, Zavanella C. Ecocardiografía bidimensional en la ausencia congénita de pericardio. Rev Arg Cardiol 1987;55:207-11.

11. Shprintzen R. Velo-Cardio-Facial syndrome: 30 years of study. Dev Disabil Res Rev 2008;14(1):3-10.

12. Kasprzak L, Der Kaloustian VM, ElliotAM, Shevell M, etal. Deletion of 22q11 in two brothers with different phenotype. Am J Med Genet 1998;75(3):288-91.

13. Nagasaki K, Itoh $M$, Naoki $O$, Kubota $M$, et al. Two cases of 22q11.2 deletion syndrome with anorectal anomalies and growth retardation. J Pediatr Endocrinol Metab 2011;24(78):585-6.

14. Colo D, Kruyt MC, Timmers-Raaijmaakers BC, Castelein RM. Scoliosis in children with chromosome 22q11.2 deletion syndrome. Ned Tijdschr Geneeskd 2012;156(4):A4298.

15. Binenbaum G,McDonald-McGinn D,Zackai E, Walker M, et al. Sclerocornea Associated With the Chromosome 22q11.2 Deletion Syndrome. Am J Med Genet A 2008;146(7):904-9. 